\title{
Reducing error in reproductive timing caused by temperature variation: interspecific differences in behavioural adjustment by fiddler crabs
}

\author{
K. A. Kerr ${ }^{1,2,3, *}$, J. H. Christy ${ }^{2}$, R. Collin ${ }^{2,3}$, F. Guichard ${ }^{1,3}$ \\ ${ }^{1}$ McGill University, Department of Biology, Montréal, Québec H3A 1B1, Canada \\ ${ }^{2}$ Smithsonian Tropical Research Institute, Apartado Postal 0843-03092, Balboa, Ancon, Panama, Panama \\ ${ }^{3}$ McGill-STRI Neotropical Environment Option (NEO), McGill University, Faculty of Science, Montréal, Québec H3A 2T6, \\ Canada
}

ABSTRACT: Many organisms time reproduction with physical and biological cycles that affect offspring survival. In the marine environment, a common pattern is the release of planktonic larvae during largeamplitude nocturnal tides, which may reduce losses due to predation. However, if the duration of embryonic development depends on temperature, changes in temperature can lead to errors in timing. Organisms may reduce such errors either by changing the timing of onset of incubation or by selecting the temperatures to which embryos are exposed. We conducted field and laboratory experiments with 2 species of fiddler crabs to examine the effects of temperature and temperature variation on the timing of larval release and synchrony of release among females. As expected, the duration of incubation increased with decreasing temperature in both species. In the field when temperature was low, Uca terpsichores released larvae earlier than expected, indicating that shifts in timing of mating reduced potential errors in timing of release. However, when temperature changed during incubation, accuracy and precision in the timing of release decreased. $U$. deichmanni maintained timing and synchrony of release despite variable temperature in the field, but in cold water in the laboratory, they incubated eggs longer than in the field and released larvae late. These differences suggest that $U$. deichmanni regulates the incubation period in the field. U. terpsichores may be less able than $U$. deichmanni to adjust to rapid variation in temperature that may accompany climate change, which could result in largescale interspecific differences in larval survival and recruitment.

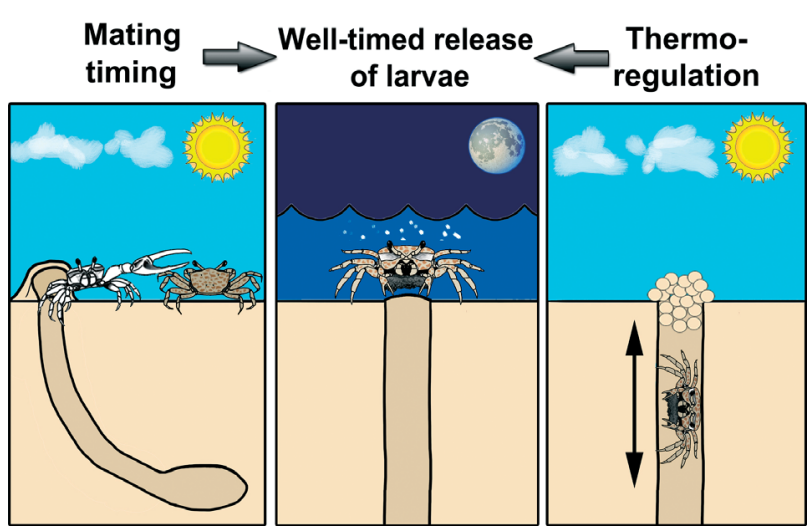

Fiddler crabs may maintain larval release during large amplitude nocturnal tides despite temperature variation by shifting timing of mating or selecting incubation temperature.

Illustration: Javier Luque

KEY WORDS: Larval release - Timing of reproduction · Variable environment - Upwelling · Timing strategies · Tidal rhythms · Uca terpsichores $\cdot$ Uca deichmanni

Resale or republication not permitted without written consent of the publisher

\section{INTRODUCTION}

Many plants and animals time reproduction with cyclically changing environmental conditions that are conducive for growth or survival of offspring or adults (Palmer 1995, Edwards \& Richardson 2004, 
Visser et al. 2006). Temperature directly affects the incubation period of ectotherms (e.g. Wear 1974). Hence, since temperature is variable in many habitats, selection should favour organisms that adjust to temperature-induced variation in the incubation period, so that they time hatching appropriately.

Changing climate has affected the timing of reproduction in many organisms (Beebee 1995, Walther et al. 2002). Some have maintained timing relative to targeted conditions, while others have not, thus reducing fitness via mismatches between peaks in hatching and optimal conditions for juvenile survival (Edwards \& Richardson 2004, Visser et al. 2006, Thackeray et al. 2010, Kordas et al. 2011). Errors in reproductive timing can be observed both as changes in the accuracy of the average timing of the population relative to targeted conditions and in the precision or synchrony of timing among individuals. These errors may result from differences in the response to variable environmental cues prior to mating or adjustment to changes in temperature once embryonic development has begun. Here we report the results of a study of the effects of temperature and changes in temperature on the accuracy and precision of larval release by 2 species of fiddler crabs.

Many tropical marine organisms experience seasonal variation in sea temperature due to winddriven upwelling of cold waters. Upwelling intensity varies within and between years, making short-term or even seasonal temperature variation a difficult cue to follow (D'Croz \& O'Dea 2007). Predictions of the effect of climate change on upwelling are conflicting (Harley et al. 2006), but they include increased variability in the intensity or timing of upwelling within a season, both of which could lead to increasing errors in reproductive timing.

Nearly all species of fiddler crabs studied to date exhibit strong reproductive rhythms culminating in the rapid release of larvae during maximum- or large-amplitude high tides, primarily at night (MANT and LANT, respectively; Christy 2011; see Video S1 in the supplement at www.int-res.com/articles/suppl/m459p001_supp/). This timing results in the swift, night-time transport of larvae by tidal currents away from shallow waters where predators of larvae are most abundant (Morgan \& Christy 1995, 1997, Hovel \& Morgan 1997, Christy 2003). The timing of hatching is phenotypically plastic; females and even embryos that are transferred between tidal regimes adjust to local tidal conditions (Morgan 1996, Weaver \& Salmon 2002, Christopher et al. 2008). Further, synchrony in release of larvae in crabs appears to be a consequence of selection for timing rather than synchrony per se (Christy 2003). Thus, there is strong evidence that both the accuracy and precision of the timing of larval release increases the survival of larvae, and possibly that of reproductive females (Christy 2011).

Despite the evidence that fiddler crabs adaptively and flexibly time larval release, there may be limits on their ability to do so. If the crabs do not adjust to temperature variation, the incubation period will vary directly with temperature, reducing the temporal accuracy of release and increasing the variability in timing among females. However, crabs may minimize these effects of temperature and maintain timing via behavioural responses. They may adjust to temperature before incubation using predictive strategies such as (1) changing the timing of mating and onset of incubation (hereafter 'mating shift'; Christy 2003), or (2) selecting incubation sites based on temperature ('site selection'; deRivera 2005, Reaney \& Backwell 2007); or they may use a responsive strategy to adjust during incubation by (3) regulating the temperature to which their embryos are exposed ('thermoregulation'). These strategies provide testable predictions about how timing and synchrony of release should vary with changes in temperature. Crabs that adjust in a predictive manner (mating shift or site selection) should accurately time larval release with the MANT when temperature is relatively constant, regardless of the actual temperature. However, if they have no ability to move during incubation, timing errors will occur if the temperature changes during incubation. Further, amongfemale synchrony in release may be low due to variability among individuals in the selection of timing of mating or sites for incubation. For the mating shift strategy, when temperature decreases, incubation period will increase, but since incubation starts earlier, release should occur before the date expected based on the incubation period. Crabs that thermoregulate throughout embryonic development should respond flexibly to short-term temperature changes and, as long as a range of temperatures is available to incubating females, they should release larvae synchronously and near the time of the MANT regardless of temperature or temperature variation.

We compared the timing and synchrony of larval release of Uca terpsichores (Crane 1941) and $U$. deichmanni (Rathbun 1935) (Fig. 1), under different temperature conditions in the field and laboratory. These species are common on low-energy sandy beaches on the Pacific coast of Panama where they live a few metres apart, with $U$. terpsichores on higher, well-drained sand. Both species mate in 
males' burrows, but they differ in how females use these burrows during incubation. After mating, female $U$. terpsichores remain underground with no connection to the surface for the duration of incubation (Christy et al. 2001), while U. deichmanni females open their burrows during low tide and are occasionally seen beside their burrow entrance (Video S2 in the supplement at www.int-res.com/ articles/suppl/m459p001_supp/). Diurnal temperature, particularly at the surface of the sediment, can fluctuate dramatically in both species' habitat during upwelling, but average temperature at the bottom of the burrow tends to be lower in $U$. deichmanni habitat. Thus, when ovigerous $U$. deichmanni open or move upwards within their burrows, they expose their embryos to a wide range of temperatures.

Considering these behavioural differences during incubation and our predictions for the timing of release using different strategies, we asked: Does a change in temperature after females become ovigerous result in larval release outside the period of LANTs (inaccurate timing), or in increased variation in the timing of larval release among females (reduced precision)? Do females that have been exposed to constant temperatures during development time release more accurately and precisely with respect to the LANT than do females that have been exposed to variable temperatures during development?

\section{MATERIALS AND METHODS}

\section{Study site}

Field and laboratory experiments were conducted on the Pacific coast of Panama near Panama City between January 2009 and August 2010. The Bay of
Panama experiences seasonal temperature variation as a result of wind-driven upwelling from January to April, when water temperature drops to $\sim 20$ to $25^{\circ} \mathrm{C}$ from the May to December average of $\sim 28$ to $29^{\circ} \mathrm{C}$ (D'Croz \& O'Dea 2007; Fig. 2). Water temperature was recorded every hour by ibutton dataloggers (Maxim Embedded Datasystems) at $1 \mathrm{~m}$ depth in the centre of Culebra Bay $\left(8^{\circ} 54^{\prime} 45^{\prime \prime} \mathrm{N}, 79^{\circ} 31^{\prime} 48^{\prime \prime} \mathrm{W}\right)$ near the Smithsonian Tropical Research Institute's (STRI) Naos Marine Laboratories (Fig. 1). Following the Panama Canal Authority, we define upwelling conditions as water temperatures $<26.6^{\circ} \mathrm{C}$. The tides in the Bay of Panama are semidiurnal with an average amplitude of $3.9 \mathrm{~m}$ and a maximum amplitude of $6.9 \mathrm{~m}$. High water during spring tides usually occurs in the early morning between 04:00 and 07:00 $\mathrm{h}$ and late afternoon between 16:00 and 19:00 h.

\section{Biology and collection of study organisms}

Both Uca terpsichores and U. deichmanni exhibit semilunar cycles of courtship, mating and larval release (Zucker 1978, 1983, Christy 2003, K. Kerr et al. unpubl.). Both species breed year round, with peaks in courtship and release of larvae usually occurring during spring tides. Females incubate their eggs in burrows that extend about $20 \mathrm{~cm}$ below the sediment surface.

Ovigerous crabs were collected from burrows at 3 sites near the Pacific entrance to the Panama Canal (Uca terpsichores: Rodman \& Playita, U. deichmanni: Puente, Fig. 1). Burrows of ovigerous U. deichmanni were identified by small piles of balls of sand covering a plugged burrow entrance. To locate the incubation chamber, we inserted a long cable tie into the burrow shaft and dug from the side of the burrow
Fig. 1. Uca deichmanni and U. terpsichores. (a) Courting male $U$. terpsichores, (b) male $U$. deichmanni (photos by K. Kerr) and (c) ovigerous female U. deichmanni (photo by A. Anker). (d) Pacific coast of Panama at the entrance to the Panama Canal, indicating the locations of collection sites (Rodman, Puente and Playita), field enclosures (Rodman), water temperature data logger (Culebra) and Smithsonian Tropical Research Institute's Naos Marine Labs (Naos) (map altered from Google Maps)

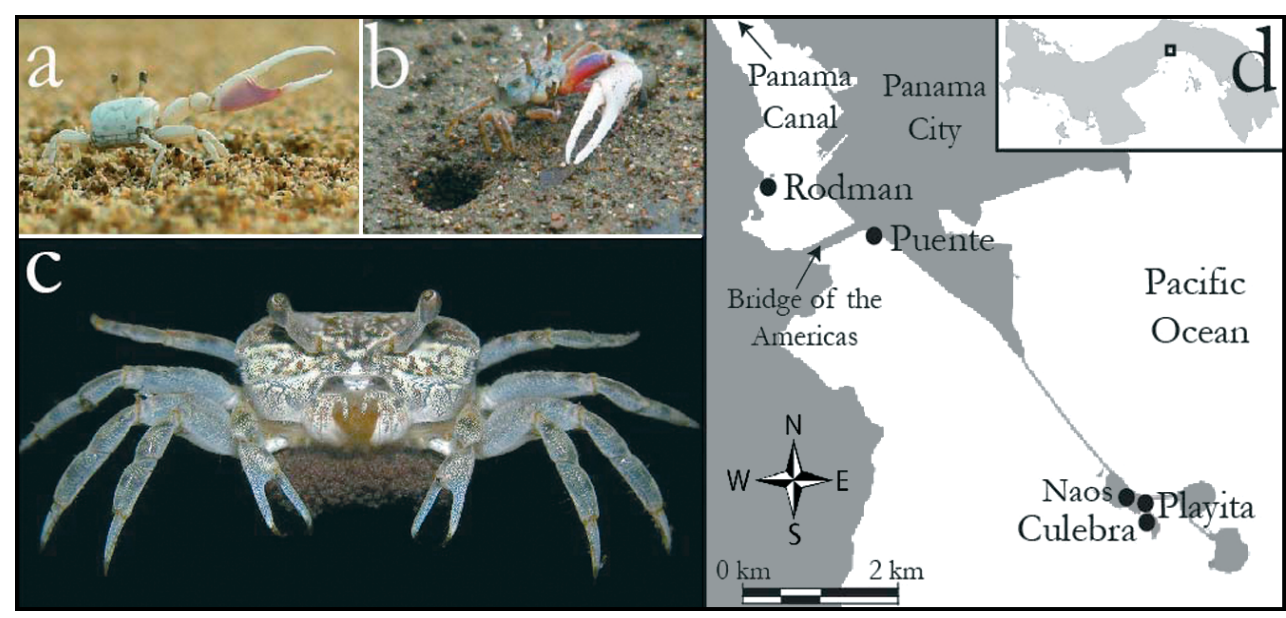




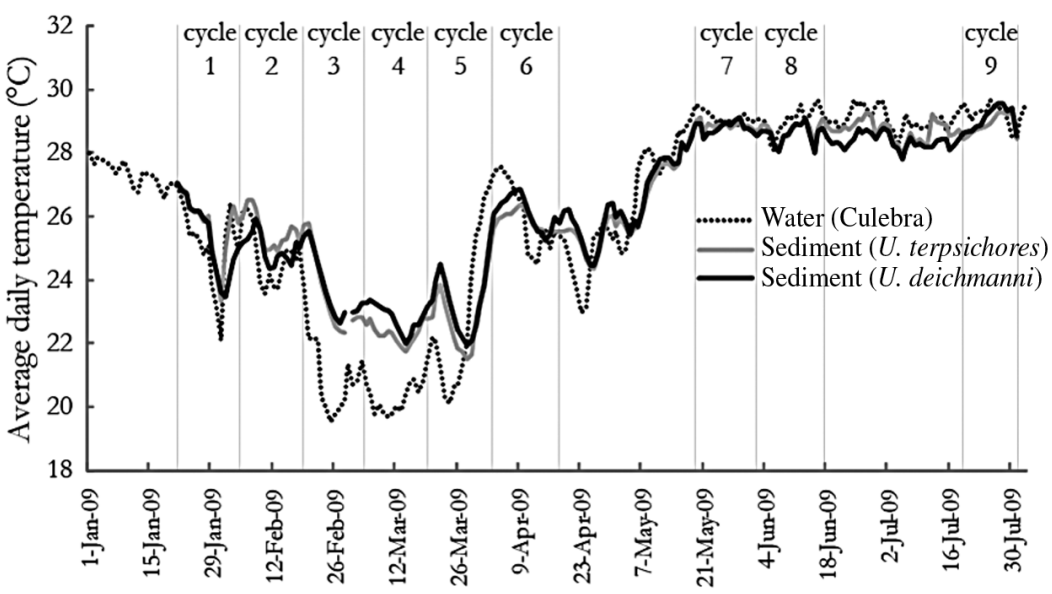

Fig. 2. Average daily water and sediment temperatures. Water temperature is from Culebra Bay on Naos Island at $1 \mathrm{~m}$ depth. Sediment temperature is from $20 \mathrm{~cm}$ depth in Uca terpsichores and U. deichmanni habitats at Rodman. Vertical lines indicate minimum amplitude tides. Upwelling conditions were recorded during cycles 2 to 6 . No or very little sampling occurred between cycles 6 and 7 and between 8 and 9

towards the cable tie to extract the female. Since ovigerous female $U$. terpsichores leave no indication of the location of their incubation chambers, we 'trenched' for them in a high-density area. First we dug a hole 30 to $40 \mathrm{~cm}$ deep and about $50 \mathrm{~cm}$ wide and then searched for incubation chambers by slowly carving away the walls of the hole creating a trench through the population. Since our females were moved from their chosen incubation site to field enclosures or the laboratory, we could not test whether females maintain reproductive timing by choosing where they incubate their eggs (site selection strategy).

\section{Field enclosures}

To determine the timing of release in the field, we deployed 3 field enclosures in the habitat of each species on a sandbar at the Rodman tidal flats between 27 January and 29 July 2009 (Fig. 1). Each enclosure was regularly stocked with ovigerous females of one of the species. The enclosures were rectangular plywood frames, $1 \mathrm{~m}$ long, $0.5 \mathrm{~m}$ wide and $0.5 \mathrm{~m}$ deep, buried about $30 \mathrm{~cm}$ into the sediment. The sides had $10 \mathrm{~cm}$ diameter holes covered by mesh, allowing the tide to gradually enter and leave the enclosures. Each day throughout the experiments, we removed all crabs not carrying eggs that were active on the surface. Thus, original inhabitants of the area inside the enclosures were removed within a few days of installation.
Before ovigerous crabs were put into the enclosures, they were individually labelled by affixing numbered tags of vinyl tape to their carapace with cyanoacrylate glue. A small sample of eggs was taken from each female's brood and, using a dissecting microscope, a single observer estimated the percentage of yolk remaining. We made burrows approximately $20 \mathrm{~cm}$ deep and $1.5 \mathrm{~cm}$ wide in the enclosures using a large screwdriver. We then placed a female within each burrow and closed the opening. On average we added 17 (range $=3$ to 62) females enclosure ${ }^{-1}$ cycle $^{-1}$, resulting in an average initial density per cycle of 34 females $\mathrm{m}^{-2}$, within the upper range of natural densities of Uca terpsichores adults ( $\sim 37$ adult burrows $\mathrm{m}^{-2}$ ).

During each daytime low tide, we stood approximately 2 to $3 \mathrm{~m}$ away from the enclosures and identified females on the surface using binoculars. The first day on which we saw a female on the surface without eggs was recorded as her date of release. A total of 291 Uca terpsichores and 281 U. deichmanni released larvae in the enclosures across 9 tidal cycles (cycles of release). Of these, $39 \mathrm{U}$. terpsichores and $94 \mathrm{U}$. deichmanni carried broods with eggs containing $100 \%$ yolk when placed in the enclosures.

Temperature was recorded every hour by an ibutton at a depth of approximately $20 \mathrm{~cm}$ in the sand in each enclosure. Ovigerous Uca terpsichores were usually collected from areas near the enclosures on the same sandbar and thus experienced no change in sediment temperature when added to the enclosures. $U$. deichmanni females were collected at 'Puente' (Fig. 1), where the sediment was on average $2.3^{\circ} \mathrm{C}$ warmer during upwelling than the temperature within the enclosures. The decrease in temperature would be expected to increase the incubation period and result in late hatching and decreased amongfemale synchrony, due to the greater absolute difference in duration of incubation among females that started the experiment with broods at different developmental stages.

\section{Laboratory experiments}

Experiments were conducted during the wet (nonupwelling) season between June and August in 2009 
and 2010 in the outdoor seawater pavilion at the Naos Laboratories. The pavilion has a roof but no walls, shielding the aquaria from direct sun and rain while providing natural light. Seawater in the pavilion is pumped from the Bay of Panama and averaged $28.9^{\circ} \mathrm{C}( \pm 0.52 \mathrm{SD})$ during the experiments. For each treatment, a 1891 insulated drum received water continuously from the seawater system and supplied water to the experimental aquaria through insulated PVC tubes. For the cold treatment, water in the drum was chilled using a Tradewind 1/5 HP Drop-in chiller.

Temperature treatments were randomly assigned to square 181 aquaria, with 3 replicate aquaria for each treatment. Females of each species were randomly assigned to treatments and placed in PVC tubes $(10 \mathrm{~cm}$ length, $3 \mathrm{~cm}$ inner diameter) with plankton mesh on the bottom. The tubes were suspended vertically in the aquaria so that the females were approximately half covered by water. Females could not change their position within the tubes, thus preventing behavioural thermoregulation. Aquaria were covered on all sides with black plastic and insulated using $1.27 \mathrm{~cm}$ thick polystyrene foam. In 2009, the tops of the aquaria were mostly covered with foam to maintain the temperature inside the aquaria, but ambient light was not completely blocked. In 2010, the tops were left open but the surface of the water between the tubes was insulated with foam to minimize the effect of air temperature on water temperature. The water was constantly mixed by aeration. Egg samples were removed from each female shortly after collection and the percent of yolk remaining was estimated. Females were checked at least once per day to determine the date of larval release.

\section{Constant temperature}

To examine the relationship between temperature and incubation period, female Uca terpsichores and $U$. deichmanni were placed in aquaria in which the water temperature corresponded to constant upwelling $\left(\sim 23^{\circ} \mathrm{C}\right.$, hereafter cold treatment), ambient non-upwelling $\left(\sim 29^{\circ} \mathrm{C}\right.$, control, hereafter warm treatment) or elevated $\left(\sim 31^{\circ} \mathrm{C}\right.$, hereafter hot treatment) temperatures. In 2010, we used only $U$. deichmanni females in only cold and warm treatments.

\section{Variable temperature}

To determine whether there is a difference in incubation period when temperature changes during development, we compared 2 treatments with variable temperatures to a control treatment with a constant temperature. All treatments had average temperatures of approximately $26^{\circ} \mathrm{C}$ (Table 1 ). The variable temperature treatments tested the effect of the timing of exposure to cold water on development period. Females and their eggs were exposed to $22^{\circ} \mathrm{C}$ water either for the first $5 \mathrm{~d}$ of the experiment ('cold early' treatment) or starting on Day 6, for the remainder of the experiment ('cold late' treatment). When not in the cold treatment, females experienced ambient non-upwelling temperatures $\left(\sim 29^{\circ} \mathrm{C}\right.$; Table 1$)$. The number of days in the second temperature depended on the duration of incubation (Table 1).

\section{Data analysis}

Most analyses were conducted using data from females that began the experiments with eggs con-

Table 1. Uca deichmanni and U. terpsichores. Summary of the variable temperature laboratory experiments. For the cold early and cold late treatments, females were switched from one temperature treatment to the other on Day 6 . The temperature variance experienced by each female between Day 1 of the experiment and the day she released her larvae was averaged among all females for each treatment. NA: not applicable; data for duration of period are mean and range, other data are mean \pm SE

\begin{tabular}{|c|c|c|c|c|c|c|c|}
\hline Treatment & $\begin{array}{l}\text { Regime } \\
\left({ }^{\circ} \mathrm{C}\right)\end{array}$ & $\begin{array}{l}\text { Cold period } \\
\text { (d) }\end{array}$ & $\begin{array}{l}\text { Warm period } \\
\text { (d) }\end{array}$ & $\begin{array}{c}\text { Temperature } \\
\left({ }^{\circ} \mathrm{C}\right)\end{array}$ & $\begin{array}{c}\text { Temp. variation } \\
\left({ }^{\circ} \mathrm{C}\right)\end{array}$ & $\begin{array}{c}\text { Incubation } \\
\text { period (d) }\end{array}$ & $\mathrm{N}$ \\
\hline \multicolumn{8}{|c|}{ U. terpsichores } \\
\hline Constant & 26 & NA & NA & $26.75 \pm 0.208$ & $1.32 \pm 0.228$ & $12.7 \pm 0.47$ & 7 \\
\hline Cold early & $22 \rightarrow 29$ & 6 & $8(7-10)$ & $26.68 \pm 0.040$ & $4.63 \pm 0.176$ & $14.0 \pm 0.55$ & 5 \\
\hline Cold late & $29 \rightarrow 22$ & $8.2(7-10)$ & 6 & $25.32 \pm 0.131$ & $9.73 \pm 0.253$ & $14.2 \pm 0.48$ & 6 \\
\hline \multicolumn{8}{|c|}{ U. deichmanni } \\
\hline Constant & 26 & NA & NA & $26.40 \pm 0.304$ & $1.11 \pm 0.395$ & $10.6 \pm 0.68$ & 5 \\
\hline Cold early & $22 \rightarrow 29$ & 6 & $6(6-6)$ & $26.13 \pm 0.049$ & $5.62 \pm 0.279$ & $12.0 \pm 0.00$ & 6 \\
\hline Cold late & $29 \rightarrow 22$ & $6.0(4-7)$ & 6 & $25.64 \pm 0.120$ & $10.77 \pm 0.271$ & $12.0 \pm 0.33$ & 9 \\
\hline
\end{tabular}


taining $100 \%$ yolk. However, small sample sizes caused us to relax this criterion for 2 analyses: (1) all yolk stages were used for the cycle by cycle analysis of timing of release in the field, (2) broods containing 90 to $100 \%$ yolk were used for the UCa terpsichores constant temperature experiments. For the laboratory experiments, since some aquaria received very few females with eggs containing $100 \%$ yolk, we pooled the data from all aquaria for each treatment, and from multiple runs of the constant temperature experiment (2 runs for each species in 2009 and 3 runs for U. deichmanni in 2010). Analyses of incubation period were conducted in the R statistical computing environment (Version 2.13.0; R Development Core Team 2011) using generalized additive models (GAMs, mgcv package in $\mathrm{R}_{i}$ Wood 2006) with a gamma probability distribution and log link function. The gamma distribution family is commonly used for describing waiting time to an event. GAMs were selected because the relationship between temperature and incubation period is non-linear. Using the 'gam' function (mgcv package) in $\mathrm{R}$, smoothed terms were fitted using thin plate regression splines with the smoothing parameters chosen by generalized cross validation (GCV) minimizing the GCV score (Wood 2006).

We tested for effects of the following predictor variables on incubation period: species, incubation temperature, temperature treatment (lab, variable temperature experiments), temperature variance (field), cycle of release (field), location (field versus lab), and interactions. The average incubation temperature and variance in incubation temperature for each female were calculated using the ibutton data between the date the female entered the aquarium or the field enclosure and the date she released her larvae. For analyses of lab data for Uca deichmanni, we also tested for an effect of year of the experiment. Year was treated as a fixed effect because it had only 2 levels (Crawley 2002). Predictor variables were removed from the model if the comparison of nested models using likelihood ratio tests (LRT), or analysis of deviance (function 'anova' in R), showed no significant difference between models with and without the variable. Model selection conducted by comparing Akaike information criterion (AIC) values of each model supports our model selection based on LRT. Continuous variables were modeled both as linear and smoothed functions to determine whether the model was improved by including the term as a nonlinear factor. In all instances, the models with nonlinear functions were a significant improvement over the linear case. GAMs also outperformed models with an exponential relationship between incubation period and incubation temperature. Initial GAMs for the field enclosures showed a non-monotonic (and thus nonsensical) relationship between temperature and incubation period, indicating overfitting of the data. Smoothing was thus increased to the point where monotonicity was achieved but the GCV score remained low. Instances where smoothing was increased from the level which minimized the GCV score are indicated. Final models are presented. Bonferroni corrections were used to adjust for multiple comparisons. Plots were produced using the GGplot2 package in $\mathrm{R}$ (Wickham 2009).

Timing of release relative to the tidal amplitude cycle was analysed using circular statistics (Zar 2010). Angles, or phase, for each day in the tidal amplitude cycle were determined by dividing $360^{\circ}$ by the number of days between successive MANTs and multiplying this daily angle increment by the day in the cycle (e.g. Day 9 in a 15 d cycle: [360/15] $\times 9=216^{\circ}$ ). The day of MANT is $0^{\circ}$. The cycle period length, i.e. the number of days between successive MANTs, ranged from 12 to 17 with an average of 15. Day of larval release expressed as an angle in degrees relative to the day of the MANT was plotted on circular plots using GGplot2 (R, Wickham 2009). We used the CircStats2010d package in Matlab (Berens 2009) to calculate circular statistics: mean angle (a), resultant vector length or dispersion $(\mathbf{R}$, range $=0-1$, randomly scattered to identical values) and $95 \%$ confidence intervals (CI) for the mean angle (see Table 3). Since our data are not unimodally distributed, we used the omnibus, or Hodges-Ajne, test for uniformity of distribution to determine whether the timing of release of larvae was significantly clustered. The omnibus test (Zar 2010) for circular uniformity asks how large the resultant vector (R) must be to indicate a non-uniform distribution without assuming a unimodal distribution. The null hypothesis states that the population is uniformly distributed around a circle (Berens 2009, Zar 2010). Thus, $\mathrm{p}_{\mathrm{o}}<0.05$ indicates that the data are significantly clustered. Synchrony in larval release among females is indicated by a significant $\mathbf{R}$ value revealed by the omnibus test. We also used the $v$-test to test the alternative hypothesis that the data points are significantly clustered around a mean angle not different from that of a specified angle. In this case, the specified angle was the day of the MANT, $0^{\circ}$. A significant result $\left(\mathrm{p}_{\mathrm{v}}<0.05\right)$ indicates that the data are significantly clustered around a mean value not different from $0^{\circ}$. However, $\mathrm{p}>0.05$ indicates that the data are uniformly distributed or that the mean angle is different from $0^{\circ}$. When the omnibus test is signifi- 
cant but the $v$-test is not, we can conclude that the releases are clustered (high precision/high synchrony) but the timing is significantly different (low accuracy) from the MANT.

\section{RESULTS}

\section{Effect of temperature}

Incubation period

Incubation period decreased non-linearly with increasing incubation temperature in both species (Figs. $3 \& 4$, Table 2). The duration of incubation in Uca deichmanni was generally shorter than in $U$. terpsichores (Figs. $3 \& 4$, Table 2). This difference was most pronounced during upwelling conditions in the field, when the average incubation period for $U$. deichmanni was $13.4 \mathrm{~d}$ compared to $18.3 \mathrm{~d}$ for $U$. terpsichores (Figs. $3 \&$ 4). In contrast, in the lab in 2009 , the difference between species at lower temperatures was minimal (Figs. $3 \& 4$, Table 2). For $U$. terpsichores, the difference in average incubation period between seasons in the field and between the cold and warm treatments in the laboratory was similar. For $U$. deichmanni, the increase in incubation period from warm to cold conditions was larger in the lab than in the field. For both species, incubation period was about half a day shorter in the hot treatment compared to the warm treatment (Figs. $3 \& 4$ ). There was a significant interaction between incubation temperature and location (lab versus field) for both species (Table 2, Fig. 4).

\section{Timing and synchrony of larval release}

In the field, both species released larvae later in the tidal amplitude cycle during upwelling than during non-upwelling conditions. However, the effect of season on release timing was stronger in Uca terpsichores, which released $4 \mathrm{~d}$ later during upwelling than during non-upwelling conditions, compared to only $2.5 \mathrm{~d}$ later for $U$. deichmanni (Fig. 5). Despite experiencing a decrease in temperature when added to the enclosures during upwelling, releases by $U$. deichmanni during both seasons were clustered (synchronous, $\mathrm{p}_{\mathrm{o}}<0.05$ ) and accurately timed relative to the MANT $\left(\mathrm{p}_{\mathrm{v}}<0.05\right.$, Fig. 5, Table 3$)$. Timing for $U$. terpsichores during non-upwelling was also accurate and precise $\left(\mathrm{p}_{\mathrm{o}}<0.05, \mathrm{p}_{\mathrm{v}}<0.05\right)$, but release among female $U$. terpsichores during upwelling was asynchronous $\left(\mathbf{R}=0.278, \mathrm{p}_{\text {o, upwelling }}=0.47\right.$; Fig. 5, Table 3).

In non-upwelling conditions in the laboratory, there was no significant difference between the timing of release by Uca deichmanni and the date of the

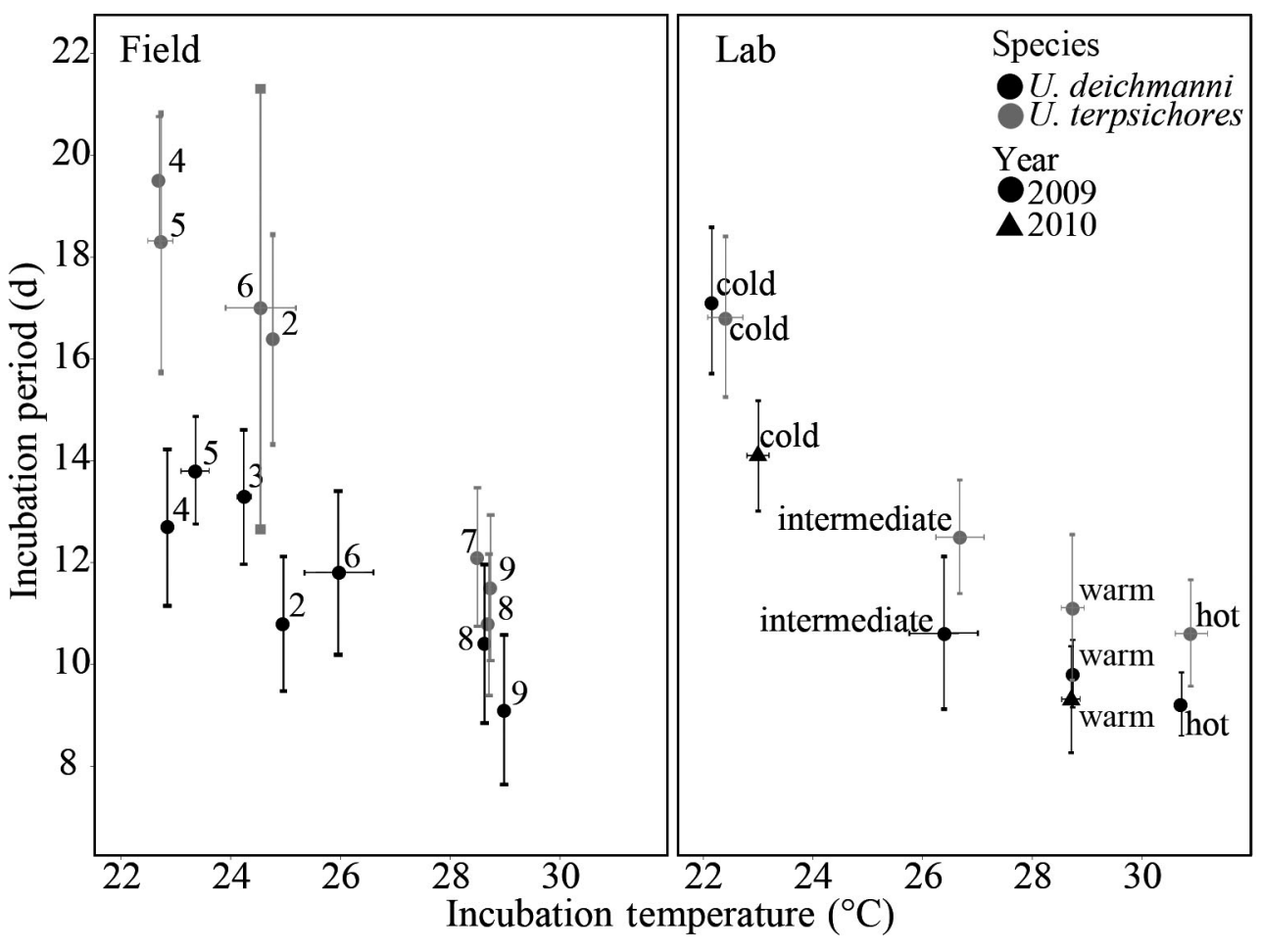

Fig. 3. Uca deichmanni and $U$. terpsichores. Mean $( \pm$ $\mathrm{SD})$ incubation period with respect to mean incubation temperature $\left({ }^{\circ} \mathrm{C}\right)$ in the field per tidal amplitude cycle (cycle number is labelled next to each point) and in the laboratory. Temperature treatments are from the constant temperature experiments and the constant temperature treatment (intermediate) from the variable temperature experiment. Eggs contained 100\% yolk at the start of the experiments except for the $U$. terpsichores lab data, which contained 90 to $100 \%$ yolk 


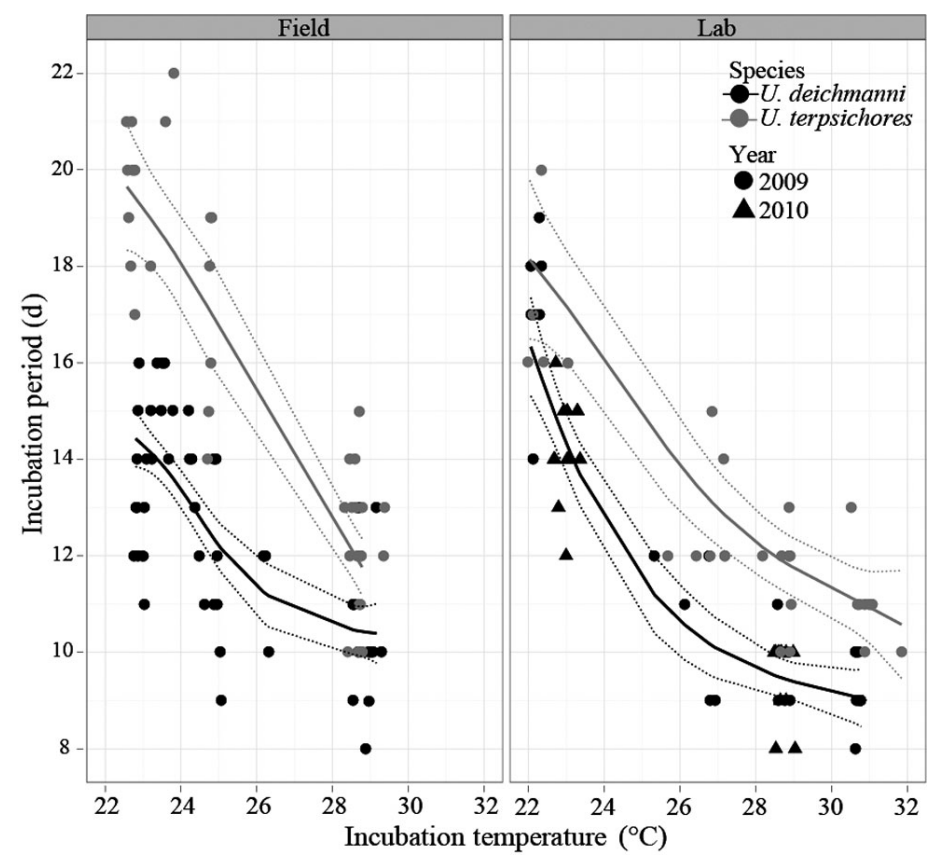

Fig. 4. Uca deichmanni and U. terpsichores. Incubation period for each female with respect to mean incubation temperature in the field and in the laboratory during the constant temperature experiments (circles and triangles represent larval releases). Solid lines = generalized additive model fit for the laboratory and field comparison (incubation period $\sim$ s(incubation temperature: location: species) + location + species, see Table $2, \mathrm{~s}()=$ smoothed variables). Dotted lines $=95 \%$ confidence intervals. Due to small sample size, we used $U$. terpsichores females carrying broods with 90 to $100 \%$ yolk for the laboratory analysis. For all other cases, females started the experiments with $100 \%$ yolk

Table 2. Uca deichmanni and U. terpsichores. Summary of generalized additive (gamma distribution) model fits to incubation period data, showing reduced models (separated by horizontal lines) ${ }_{i}^{*} \mathrm{p}<0.05, \bullet=0.1>\mathrm{p}>0.05, \S=\mathrm{p}<$ Bonferronicorrected family-level significant threshold, ns = non-significant at this threshold. Variables for which smoothing was increased to reduce overfitting are italicized. Effective degrees of freedom (edf), a representation of the level of nonlinearity, is provided for all smoothed variables (linear $=1$, nonlinear $>1$ ). $\mathrm{N}$ : total number of females included in the analysis. $s($ var): smoothed variable, T: incubation temperature, TV: temperature variance during incubation, TT: temperature treatment, S: species, L: location (field or laboratory)

\begin{tabular}{|c|c|c|c|c|c|c|}
\hline & Species & $\mathrm{N}$ & $\begin{array}{c}\text { Deviance } \\
\text { explained } \\
(\%)\end{array}$ & Model terms & edf & $\begin{array}{l}\text { Coefficient esti- } \\
\text { mates: incubation } \\
\text { period }(d) \pm S E\end{array}$ \\
\hline \multirow[t]{2}{*}{ Field enclosures } & U. terpsichores & 37 & 81.6 & $\begin{array}{l}\text { Intercept }{ }^{*}, \S \\
S(T)^{*}, \S\end{array}$ & \multirow[t]{2}{*}{2.51} & $15.3 \pm 1.02$ \\
\hline & U. deichmanni & 94 & 70.3 & $\begin{array}{l}\text { Intercept* }{ }^{*}, \S \\
S(T \times T V)^{*}, \S\end{array}$ & & $12.7 \pm 1.01$ \\
\hline \multirow[t]{2}{*}{$\begin{array}{l}\text { Laboratory constant } \\
\text { temperature }\end{array}$} & U. terpsichores & 32 & 76.8 & $\begin{array}{l}\text { Intercept }^{*}, \S \\
\mathrm{s}(\mathrm{T})^{*}, \S\end{array}$ & 1.73 & $12.4 \pm 1.02$ \\
\hline & U. deichmanni & 57 & 89.7 & $\begin{array}{c}\text { Intercept }{ }^{*}, \S \\
\mathrm{s}(\mathrm{T})^{*}, \S \\
\text { year }(2010)^{*}, \text { ns }\end{array}$ & 2.44 & $\begin{array}{l}11.7 \pm 1.02 \\
11.1 \pm 1.03\end{array}$ \\
\hline \multirow[t]{2}{*}{$\begin{array}{l}\text { Laboratory variable } \\
\text { temperature }\end{array}$} & U. terpsichores & 18 & 40.4 & $\begin{array}{c}\text { Intercept }^{*} \\
\text { TT• } \text { ns (cold early) }^{\text {(cold late) }}\end{array}$ & & $\begin{array}{l}12.7 \pm 1.03 \\
14.0 \pm 1.05 \\
14.1 \pm 1.05\end{array}$ \\
\hline & U. deichmanni & 20 & 89.5 & 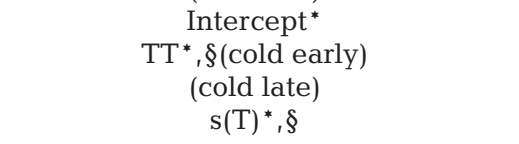 & 8.39 & $\begin{array}{l}10.9 \pm 1.04 \\
12.7 \pm 1.05 \\
11.4 \pm 1.05\end{array}$ \\
\hline $\begin{array}{l}\text { Field and laboratory } \\
\text { comparison }\end{array}$ & Both & 220 & 78.9 & $\begin{array}{c}\text { Intercept }^{*}, \S \\
\mathrm{S}(U . \text { terpsichores })^{*}, \S \\
\mathrm{L}(\text { lab })^{*}, \mathrm{~ns} \\
S(T) \times L(\text { field }) \times S(U . \text { deichmanni })^{*}, \S \\
S(T) \times L(\text { lab }) \times S(U . \text { deichmanni })^{*}, \S \\
S(T) \times L(\text { field }) \times S(U . \text { terpsichores })^{*}, \S \\
S(T) \times L(\text { lab }) \times S(U . \text { terpsichores })^{*}, \S\end{array}$ & $\begin{array}{l}2.07 \\
2.46 \\
1.66 \\
2.35\end{array}$ & $\begin{array}{l}12.2 \pm 1.01 \\
15.1 \pm 1.02 \\
11.6 \pm 1.02\end{array}$ \\
\hline
\end{tabular}


MANT. In cold conditions in 2010, U. deichmanni females released larvae synchronously $\left(\mathrm{p}_{\mathrm{o}}\right.$, cold, $2010<$ 0.05), but significantly later than the MANT (Table 3). In 2009, U. deichmanni releases were not synchronous $\left(\mathrm{p}_{\mathrm{o}}\right.$, cold, $\left.2009=0.375\right)$, but all releases occurred after the safe period. In the warm treatment, $U$. terpsichores released larvae precisely $\left(\mathrm{p}_{\mathrm{o}}<\right.$ 0.05 ) and accurately, but in cold conditions releases were asynchronous $\left(p_{o}>0.05\right)$, and occurred after the safe period (Fig. 5, Table 3).

The timing and synchrony of release were similar in the laboratory and the field under warm conditions for both species, but Uca deichmanni released later in cold conditions in the laboratory. In the field, the difference between seasons in the incubation period of $U$. deichmanni (3.1 d) was well reflected in the change in the timing of larval release (2.5 d later during upwelling). For U. terpsichores, incubation period was $6.1 \mathrm{~d}$ longer during upwelling, but larvae were released only $4 \mathrm{~d}$ later. This suggests that for $U$. terpsichores, fertilization occurred $\sim 2 \mathrm{~d}$ earlier during upwelling conditions. In the laboratory, both species demonstrated similar differences in the timing of release and incubation period across temperature treatments, reflecting their inability to make behavioural adjustments.

\section{Effect of temperature variation}

Incubation period

In the field, the 2 species differed in how the duration of incubation was affected by the combination of incubation temperature and temperature variance or hatching cycle. All models of incubation period as a function of temperature for Uca terpsichores were statistically equivalent; therefore, we present the simplest model (Table 2). Models of incubation period for $U$. deichmanni that included the interaction between incubation temperature and either cycle of release or temperature variance during incubation were significantly better than a model with only incubation temperature (Table 2). Temperature variation differed among cycles (Fig. 2), and for U. deichmanni, average incubation period per cycle did not directly follow average incubation temperature (Fig. 3). For U. deichmanni, larger variance in temperature during incubation had the effect of further increasing incubation periods when temperature was low.

In the laboratory, incubation period was longer when females experienced variable compared to constant temperature with the same mean (Tables 1 $\& 2$ ). The pattern was the same for both species,
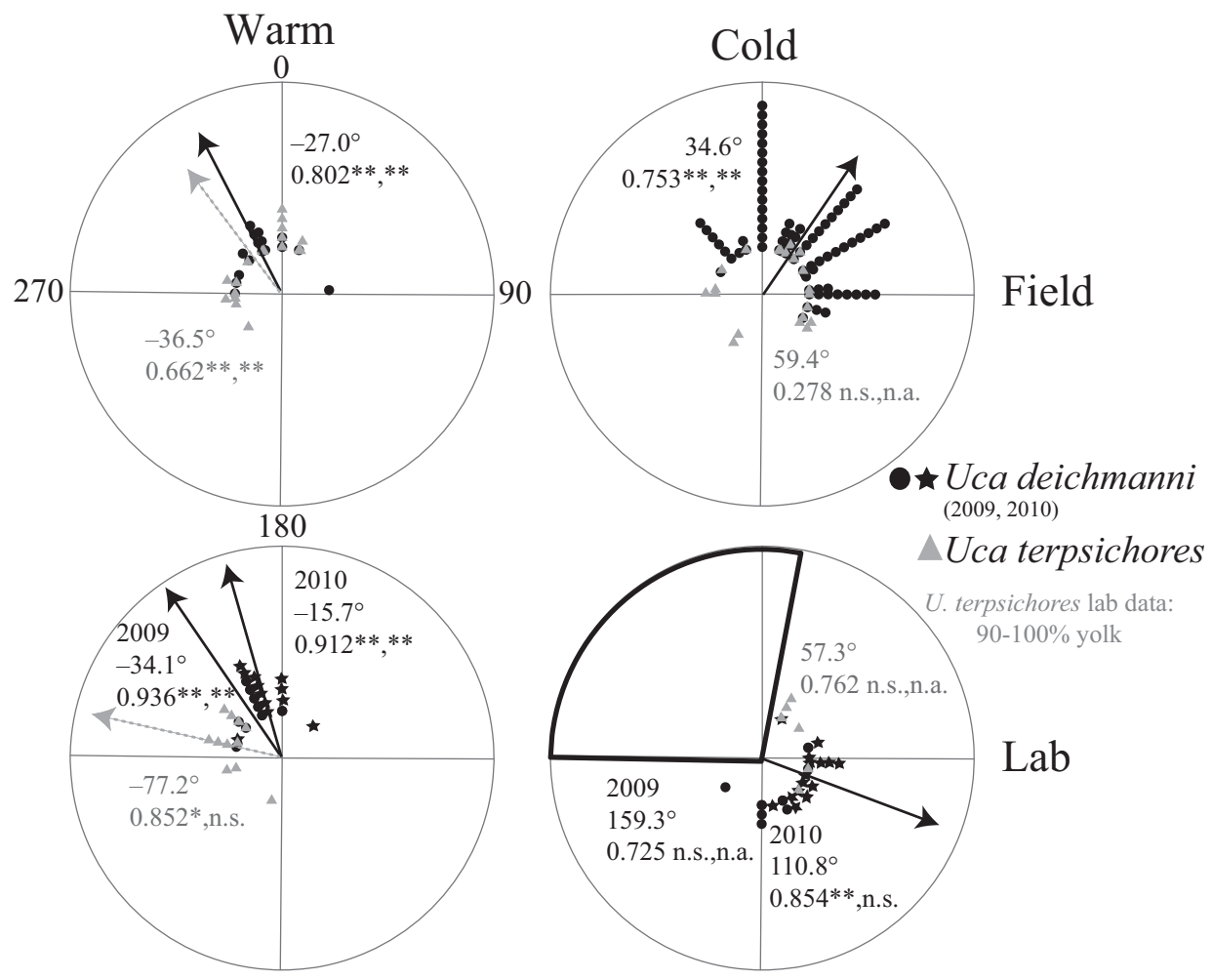

Fig. 5. Uca deichmanni and U. terpsichores. Circular plots of the timing of larval release relative to the maximum-amplitude nocturnal tide $\left(\mathrm{MANT}, 0^{\circ}\right)$ in the field and in the laboratory with constant temperatures. The circumference of each circle represents a pooled tidal amplitude cycle during 1 season or temperature treatment $\left(1\right.$ day $\approx 24^{\circ}$ ). Symbols show the day that an individual female released her larvae. Arrows indicate the mean angles of larval release (a) and are scaled to the length of the mean vector value $(\mathbf{R})$, indicating the strength of clustering of data around the mean angle. Circular statistics $(a, \mathbf{R}$ and significance levels of ${ }^{*} p<0.05,{ }^{* *} p<$ 0.01 or $n s=p>0.05$ for the omnibus and $v$-tests, respectively). The sector of the circle outlined in black (lower right: cold lab data) spans a period with large-amplitude tides that peak before dawn when it should be relatively safe for females to release their larvae. Additional information in Table 3 
Table 3. Uca deichmanni and $U$. terpsichores. Descriptive circular statistics for timing of larval release in field enclosures and during constant temperature lab experiments: mean angle (a), 95\% confidence intervals (CI), resultant mean vector length (R), p value for the omnibus test for circular uniformity ( $\mathrm{p}_{\mathrm{o}}$ if significant, the data points are not uniformly distributed), $\mathrm{p}$ value for the $v$-test for an expected mean angle of $0^{\circ}\left(\mathrm{p}_{\mathrm{v} i}\right.$ if significant, the data are significantly clustered around a mean value not different from the maximum-amplitude nocturnal tide, MANT, $0^{\circ}$ ). Bold $p$ values: instances when data are clustered at a mean angle significantly different from the MANT. Brood stages are the $\%$ yolk of females' broods at the start of the experiments that were included in the analysis. NA: not applicable

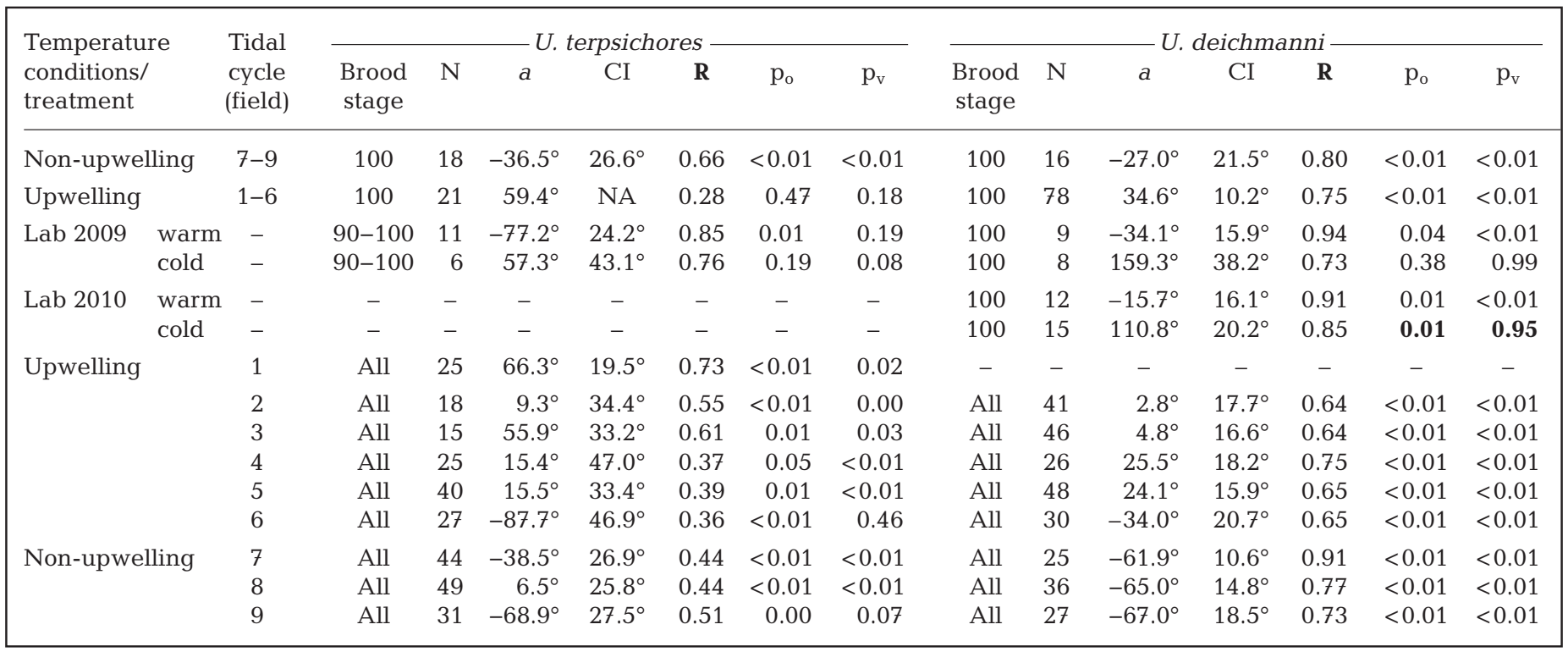

although not significant for Uca terpsichores $(\mathrm{p}=$ 0.08 ) and significant for $U$. deichmanni prior to the Bonferroni correction for multiple comparisons $(\mathrm{p}=$ 0.02; Tables $1 \& 2$ ). For $U$. deichmanni, even the small range of incubation temperatures experienced by females $\left(25.3\right.$ to $\left.26.9^{\circ} \mathrm{C}\right)$ resulted in a significant effect on incubation period. For $U$. terpsichores, inclusion of incubation temperature did not significantly improve model fit, thus it was not included in the final model (Table 2).

\section{Timing and synchrony of larval release}

Low synchrony of release among females during the upwelling season could reflect either: (1) synchronous releases during each cycle of reproduction but changes in timing of release from one cycle to the next, or (2) a lack of synchrony during individual cycles of reproduction. Since temperature varies during an upwelling season, changes in timing and synchrony from cycle to cycle provide insight into how crabs respond to changing temperature. The low synchrony of hatching by Uca terpsichores in the field during the upwelling season is the result of both variation in timing of larval release from cycle to cycle, and low synchrony during Cycles 4 to 6 (see $\mathbf{R}$ values, Fig. 6, Table 3). During upwelling, U. terpsi- chores released larvae near the MANT when temperature had been relatively constant (Cycles 2 and 4 ) or without a distinct temperature trend during incubation (Cycle 5; Figs. 2, 5 \& 6, Table 4). When average temperature increased or decreased between cycles, $U$. terpsichores released earlier or later, respectively (Cycles 1, 3, 6; Figs. 6 \& 7a). Late in Cycle 5, when females that would release in Cycle 6 were already incubating eggs, the sediment temperature increased by $4^{\circ} \mathrm{C}$ within a few days (Fig. 2). This caused a $2.4^{\circ} \mathrm{C}$ increase in average temperature between Cycles 5 and 6 and larval release by $U$. terpsichores was significantly earlier than the MANT (Figs. $6 \& 7 \mathrm{a}$, Table 3). In contrast, large shifts in timing and synchrony of release among cycles were not observed for Uca deichmanni (Fig. 6). Timing of release was not related to changes in temperature between successive cycles (Fig. 7a), but was strongly correlated with temperature during the current cycle (Fig. 7b).

Table 4 compares temperature conditions and observed timing of release with that expected if the crabs (1) do not adjust to temperature variation, (2) shift timing of mating and (3) thermoregulate. Results for Uca deichmanni contrast with expectations if females do not adjust to temperature variation (no response); release timing for U. deichmanni was 'on time' except during the 2 coldest tidal 

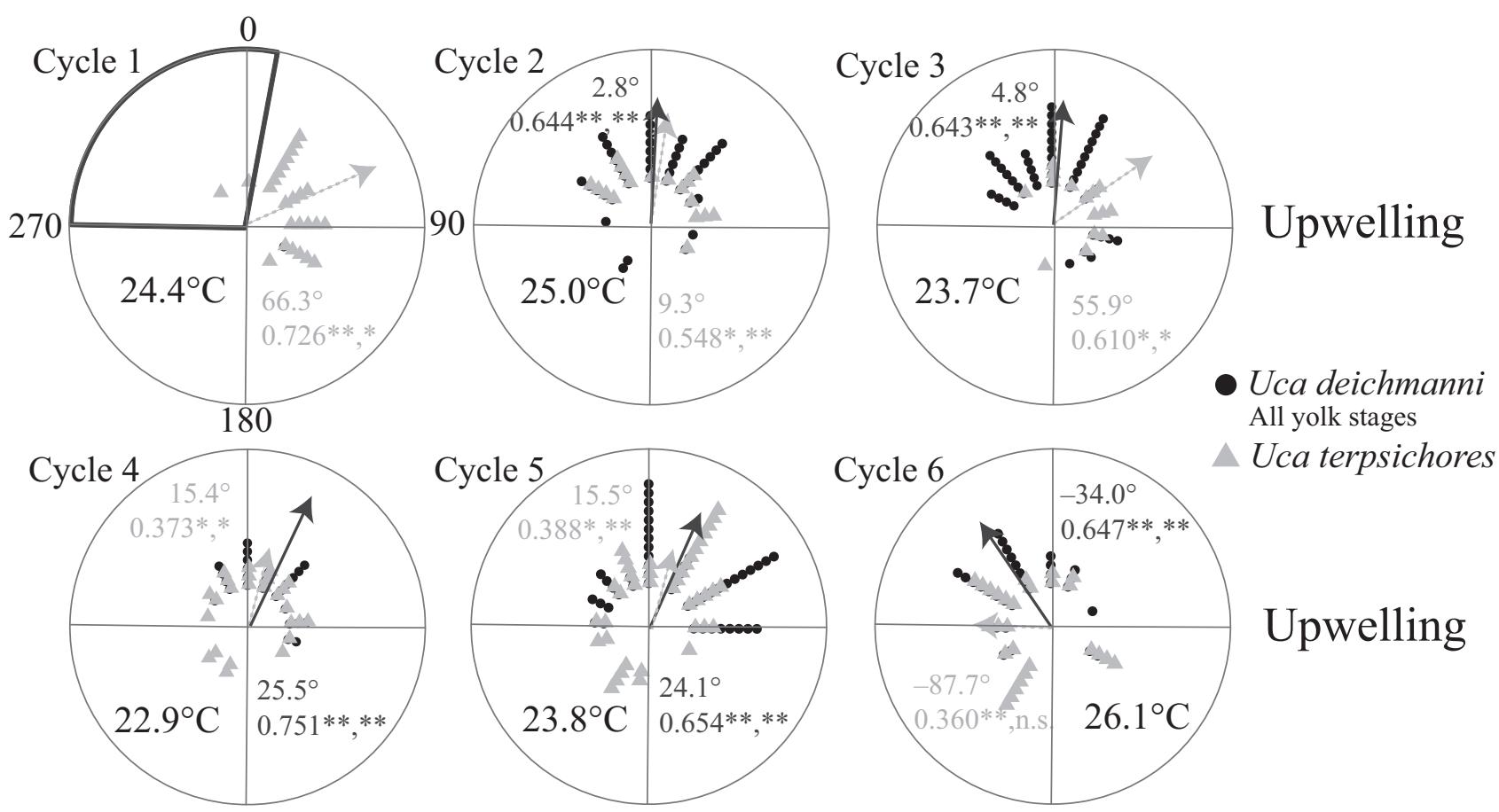

All yolk stages

Uca terpsichores
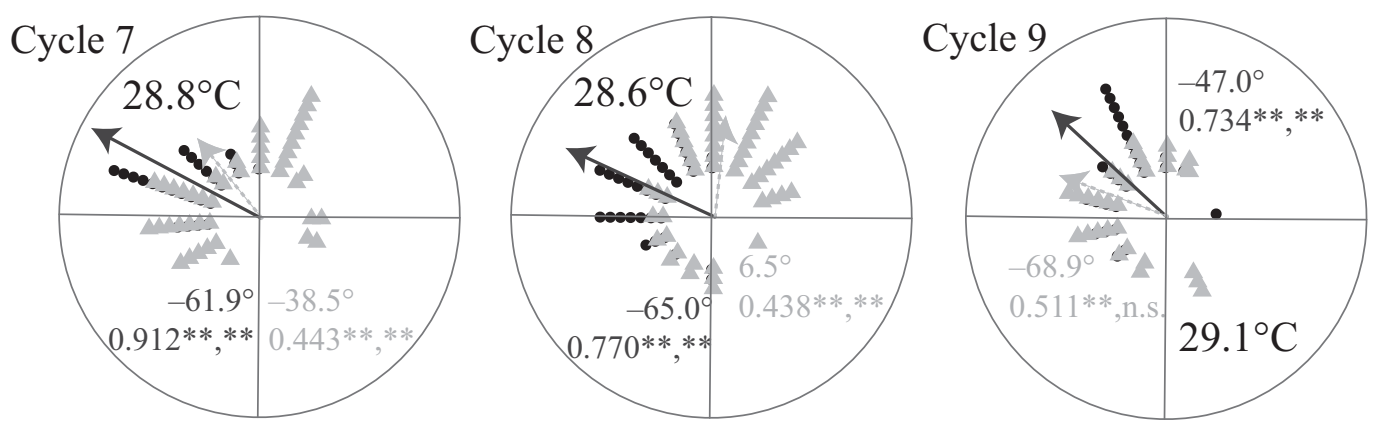

No upwelling

Fig. 6. Uca deichmanni and U. terpsichores. Circular plots of the timing of larval release by females of each species in the field enclosures relative to the maximum-amplitude nocturnal tide (MANT, $0^{\circ}$ ). The circumference of each circle represents 1 tidal amplitude cycle (1-6 during upwelling conditions, 7-9 during non-upwelling conditions, average temperature of all enclosures shown for each cycle). Females carrying eggs in all developmental stages were included. Other details follow Fig. 5 legend. Additional information in Table 3

cycles when they released $\sim 1 \mathrm{~d}$ late (Fig. 6, Tables 3 \& 4). This maintenance of timing despite temperature changes during incubation also contrasts with expected timing for the mating shift strategy. On the other hand, as predicted for the mating shift strategy, timing for $U$. terpsichores was on time for cycles when temperature had been relatively constant, but was affected by changes in temperature that occurred during incubation. With the caveat that we are unable to rule out any of the 3 strategies for either species, our results fit best with the mating shift strategy for $U$. terpsichores and the behavioural thermoregulation strategy for $U$. deichmanni.

\section{DISCUSSION}

This study revealed interspecific differences in the ability of 2 species of fiddler crabs to maintain reproductive timing during short-term temperature changes. Predictions for effects of climate change on upwelling are conflicting; upwelling may intensify (Bakun 1990, McGregor et al. 2007, Narayan et al. 2010), occur less often (Collins et al. 2010) or increase in variability (Snyder et al. 2003, Schwing et al. 2006, Barth et al. 2007). Increased temperature variability and upwelling intensity may affect species abundances and community structure as a result of differences in response among species. 
Table 4. Uca deichmanni and U. terpsichores. Predicted and actual timing of larval release given different responses by females (see Introduction). Predictions are compared to temperature conditions and the observed timing of release in the field. Temperature $\left({ }^{\circ} \mathrm{C}\right)$ per cycle refers to that of the entire tidal amplitude cycle; incubation temperature is specific to data between the date that females with $100 \%$ yolk were added to enclosures and the date they released (both species combined). Since mating (and decisions of when to mate) occur in the preceding cycle, the change in average temperature between the current and preceding cycle is included. Changes in temperature of $>1{ }^{\circ} \mathrm{C}$ are accompanied by the direction of change: $\downarrow=$ decreasing, $\uparrow=$ increasing, $\leftrightarrow$ = relatively stable, $\sim=$ variable with no overall trend. NA: not applicable

\begin{tabular}{|c|c|c|c|c|c|c|c|c|c|}
\hline & \multirow[b]{2}{*}{$\begin{array}{c}\text { Cycle } \\
(\text { Mean } \pm \text { SD) }\end{array}$} & \multirow{2}{*}{\multicolumn{2}{|c|}{\begin{tabular}{cc}
\multicolumn{2}{c}{ Temperature } \\
Incubation & State, trend \\
$($ Mean $\pm \mathrm{SD})$ & (current cycle)
\end{tabular}}} & \multirow[b]{2}{*}{$\begin{array}{l}\text { Change from } \\
\text { previous cycle }\end{array}$} & \multicolumn{3}{|c|}{$\ldots$ Predicted timing of hatching } & \multicolumn{2}{|c|}{ Hatching results } \\
\hline & & & & & $\begin{array}{l}\text { No } \\
\text { response }\end{array}$ & $\begin{array}{l}\text { Mating } \\
\text { shift }\end{array}$ & $\begin{array}{l}\text { Thermo- } \\
\text { regulation }\end{array}$ & $\begin{array}{l}\text { U. terpsi- } \\
\text { chores }\end{array}$ & $\begin{array}{c}\text { U.deich- } \\
\text { manni }\end{array}$ \\
\hline 1 & $24.42 \pm 0.94$ & NA & Intermediate, $\downarrow$ & $>1 \downarrow$ & Late & Late & On time & Late & NA \\
\hline 2 & $25.26 \pm 0.49$ & $24.93 \pm 0.562$ & Intermediate, & $<1$ & Late & On time & On time & On time & On time \\
\hline 3 & $23.42 \pm 1.22$ & $24.34 \pm 0.930$ & Low, $\downarrow$ & $>1 \downarrow$ & Late & Late & On time & Late & On time \\
\hline 4 & $22.38 \pm 0.67$ & $22.80 \pm 0.420$ & Low $_{1} \leftrightarrow$ & 1 & Late & On time & On time & On time & Late \\
\hline 5 & $23.38 \pm 1.60$ & $23.28 \pm 0.998$ & Low, $\uparrow$ & 1 & Late & On time/early & On time & On time & Late \\
\hline 6 & $25.79 \pm 0.51$ & $24.79 \pm 1.404$ & Intermediate, $\leftrightarrow$ & $>>1 \uparrow$ & On time/late & Early & On time & Early & On time \\
\hline 7 & $28.83 \pm 0.49$ & $28.48 \pm 0.504$ & High, $\leftrightarrow$ & $>1 \uparrow$ & On time & Early & On time & On time & On time \\
\hline 8 & $28.68 \pm 0.46$ & $28.63 \pm 0.268$ & High, $\leftrightarrow$ & $<<1$ & On time & On time & On time & On time & On time \\
\hline 9 & $28.93 \pm 0.47$ & $28.87 \pm 0.283$ & High, $\leftrightarrow$ & $<<1$ & On time & On time & On time & On time & On time \\
\hline
\end{tabular}

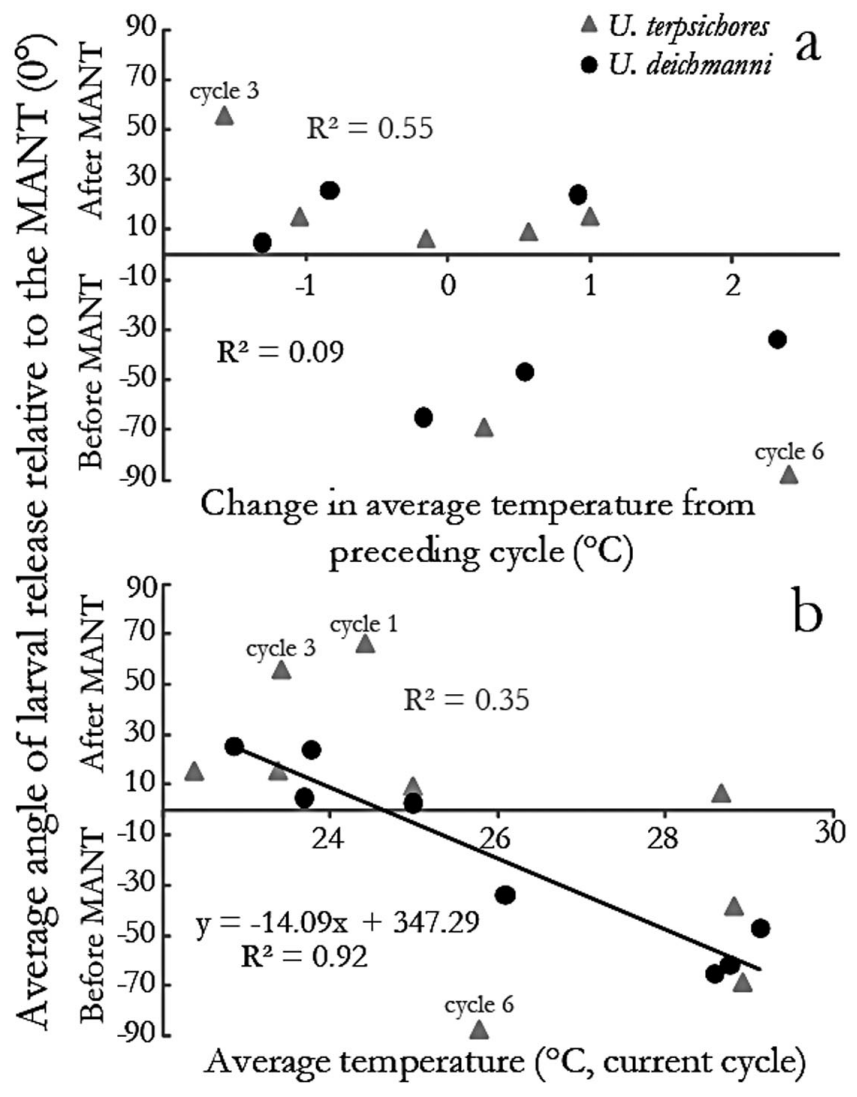

Fig. 7. Uca deichmanni and U. terpsichores. Average timing of larval release (angle) per tidal amplitude cycle relative to the maximum-amplitude nocturnal tide $\left(\mathrm{MANT}, 0^{\circ}\right)$ in relation to (a) change in temperature between the current and preceding tidal cycle and (b) temperature for the cycle during which larvae were released. Amplitude decreases with increasing angle

\section{Methods of adjustment to variable temperature}

Some fish and amphibians alter the timing of hatching by either prolonging or shortening time spent in the egg stage (Smyder \& Martin 2002, Warkentin 2011a,b); however, decapod crustaceans have not been reported to hatch at different stages in development. Crabs that live in cold temperate waters exhibit weak rhythms linked to tidal amplitude and low synchrony in release, indicating that they do not curtail or prolong embryonic development to release larvae only during large-amplitude tides (Morgan et al. 2011). Decapod embryos generally hatch with little to no yolk remaining, and newly hatched larvae are vulnerable to starvation, making prolongation of incubation until conditions improve unlikely (Anger et al. 1981, Olson \& Olson 1989, but see Duguid \& Page 2011 for an example of a coldwater species that can enter into diapause for extended periods).

By selecting incubation sites, some animals control temperature-dependent characteristics that affect the fitness of hatchlings (Patterson \& Blouin-Demers 2008, Angilletta et al. 2009, Dvořák \& Gvoždík 2010, Huang \& Pike 2011, Pike et al. 2012). Females of fiddler crab species that select thermal environments for incubation make choices that are predictable across the tidal cycle and between seasons. In Australia, Uca mjoebergi females that mated earlier in the tidal cycle chose mates with wider, cooler burrows, thus choosing longer incubation periods for their embryos (Reaney \& Backwell 2007). Further, as temperature changed with the season, females 
changed their preferences in a manner that may allow them to maintain release during LANTs (Milner et al. 2010). In California, USA, female U. crenulata also chose mates based on burrow characteristics, and these choices affected their ability to release larvae on time (deRivera 2005).

Our results and data on daily variation in courtship intensity (a direct correlate of the onset of mating and incubation, Christy et al. 2001) indicate that Uca terpsichores mate earlier in the cycle when temperature decreases (K. Kerr et al. unpubl.). While most other examples of changes in timing of mating in response to temperature are for seasonally breeding organisms, some fishes reproduce cyclically throughout the year and adjust mating timing with respect to temperature. As temperature decreases, these fishes either spawn earlier in the day so that larvae hatch at dusk, or, similar to $U$. terpsichores, spawn earlier in the tidal cycle to maintain timing of hatching during spring tides (Yamahira 1997, Kokita \& Nakazono 2000, Asoh \& Yoshikawa 2002).

Uca deichmanni does not appear to change the timing of mating in response to temperature, but maintained well-timed, synchronous release of larvae in the field despite temperature variation. Ovigerous $U$. deichmanni are regularly observed excavating their burrows and occasionally move onto the surface during low tide (Video S2). Changes in fiddler crab body temperature of $10^{\circ} \mathrm{C}$ have been recorded during movements between the sand surface and the burrow during low tide (Smith \& Miller 1973). We recorded a maximum temperature difference of $13.6^{\circ} \mathrm{C}$ between the surface and $20 \mathrm{~cm}$ depth during low tide in $U$. deichmanni habitat (K. Kerr unpubl. data). This vertical temperature range is equal to that observed in $U$. terpsichores habitat, but the average and minimum temperatures are generally lower in $U$. deichmanni habitat during upwelling, indicating that they may be more affected by temperature variation during upwelling. Ovigerous U. deichmanni expose their eggs to a wide range of temperatures as they move upward in the sediment, and they may thereby control the development rate of their embryos.

Behavioural thermoregulation by mothers occurs in viviparous and ovoviviparous reptiles (Shine \& Harlow 1993, Bernardo 1996, Shine 2005) and has been reported for some insects (Danks 2002). Although behavioural regulation of incubation periods by marine animals is not well documented, some species respond behaviourally to temperature variation including short-term changes in behaviour in response to upwelling (Sanford 1999, Silva et al. 2007). Small but potentially important differences in temperature be- tween the habitats of these 2 species, such as slightly higher sediment stability, poor drainage and thus lower risk of desiccation stress in the habitat of $U C a$ deichmanni compared to that of $U$. terpsichores, may make vertical movement in the sediment especially beneficial for $U$. deichmanni with respect to timing of release. These behavioural differences have likely conferred differing abilities to maintain timing of release in the face of short-term temperature variation.

\section{Timing errors in larval release}

In contrast to Uca deichmanni, ovigerous female $U$. terpsichores were almost always found in burrow chambers lacking connections to the surface and were never observed outside of burrows, supporting the idea that they remain at a fixed location during incubation (Christy et al. 2001). This inability to adjust to temperature variation after the onset of incubation and a range of thermal histories experienced among females due to local variation in sediment temperature or different dates of fertilization results in reduced accuracy and synchrony in timing of larval release. Crabs that live in warm temperate zones exhibit low synchrony in the timing of larval release in the spring when temperature is more variable (Wheeler 1978, Dollard 1980, Christy 1982) and crabs in cold temperate zones affected by upwelling exhibit low synchrony in general (Morgan et al. 2011). Although changing the timing of mating can compensate for the effects of relatively constant lower temperatures, it is a predictive strategy based on past temperatures and does not provide U terpsichores with sufficient flexibility to prevent timing errors when temperature changes rapidly.

For the 2 species of fiddler crabs we studied, adults and embryos experience temperatures of $\sim 28^{\circ} \mathrm{C}$ during 9 mo of the year while upwelling conditions are present only for a few months, with temperatures of $23^{\circ} \mathrm{C}$ generally only for a few days or weeks. If the proportion of development completed per day in the constant temperature treatments is considered, the longer development period in the variable treatments can be explained by the nonlinear relationship between temperature and incubation period wherein the effect of temperature on development may be asymmetric around the mean (Georges et al. 2005, this study; Fig. 4). In the variable treatments, development was slowed more by a few days in the cold temperature treatment than by a temperature of $26^{\circ} \mathrm{C}$ throughout development. Thus, in the field, rapid decreases in temperature that often occur dur- 
ing upwelling impose a non-linear increase in incubation period for which Uca terpsichores is unable to compensate, and timing errors result.

In insects, reptiles and amphibians, diurnal fluctuating temperature can lengthen, shorten or have no effect on incubation period depending on the magnitude of fluctuations and the mean temperature relative to the species' normal development range (Hagstrum \& Milliken 1991, Shine et al. 1997, Ashmore \& Janzen 2003, Du \& Shine 2010). When Uca deichmanni incubate eggs under upwelling conditions, forays to the surface of the sand or vertical movements within the shaft of the burrow introduce the type of temperature fluctuations that accelerate development rate in insects, reptiles and amphibians (Hagstrum \& Milliken 1991, Georges et al. 2005). This behaviour may thus counteract the slowing effects of longer-term temperature decreases allowing them to maintain timing of hatching in nature. However, when temperature is very low, limited periods of access to sand that is warmed during the low tides may not be sufficient to maintain timing. The largest amplitude tides occur just before sunrise and sunset, and $U$. deichmanni release larvae during the morning high tide (K. Kerr et al. unpubl. data). Hence, when $U$. deichmanni release larvae even $1 \mathrm{~d}$ after the MANT, they risk doing so during daylight when mortality rates from predation are higher than at night. In contrast, $U$. terpsichores females may reduce predation risk imposed by timing errors by shifting larval release to the evening high tide when the morning tide occurs after sunrise (J. Christy \& P. Backwell unpubl. data).

Morphology or behaviour of larvae may also reduce predation risk. However, the larvae of both of our focal species are poorly defended based on morphology (small spines, dark chromatophores and red or maroon yolk; Morgan \& Christy 1995). The larvae of some Uca species exhibit rhythms in swimming activity linked to the tidal cycle which may help larvae avoid their predators. U. terpsichores larvae do not exhibit such swimming rhythms and it is not known if $U$. deichmanni larvae do (López-Duarte et al. 2011). Thus for our species, timing errors are expected to play an important role in early larval survival.

Our results indicate that these 2 fiddler crab species have different abilities to respond to changes in upwelling conditions. An increase in temperature variability would be expected to reduce the early larval survival in Uca terpsichores to a greater degree than in $U$. deichmanni. However, intensified upwelling may push the limits of $U$. deichmanni's ability to behaviourally regulate incubation period, while $U$. terpsichores may better adjust to low but constant temperature. Thus, changes in upwelling intensity or variability may affect species abundances through differences in larval survival and recruitment and result in large-scale phenotypic and community effects.

Acknowledgements. We acknowledge the field, lab and logistical assistance of the following people in Panama: N.H. Muñoz, S. Muñoz, D.A. Haskell, N. Sanjines, Z. Joly-Lopez, A. Cornejo, J. Luque, C. Bonilla, J.I. Sánchez, A. Verlade, M. Batista, G. Alvarez, K. McDonald, M. Salazar, A. Bilgray and N. Gomez. Funding was provided by a Smithsonian Tropical Research Institute (STRI) Short-term Fellowship granted to K.A.K., National Science and Engineering Research Council of Canada (NSERC) grant to F.G., Post Graduate Scholarship (NSERC PGS D) to K.K. and Quebec Ocean funding of F.G. and K.A.K. We thank the Unidad Administrativa de Bienes Revertidos of the Ministerio de Economía y Finanzas, the Servicio Nacional Aeronaval and the Autoridad del Canal de Panama (ACP), Republic of Panama, for access to the old Rodman Naval Base and its adjacent tidal flats on the west bank of the Panama Canal, C. García de Paredes of La Playita de Amador Resort and Marina for access to 'La Playita' on Naos Island and STRI's Culebra Nature Centre for access to Culebra Bay. We thank E. Pedersen and T. Gouhier for advice and assistance with data analysis, as well as A. Hendry and H. Lessios for helpful comments during development of the project.

\section{LITERATURE CITED}

Anger K, Dawirs RR, Anger V, Costlow JD (1981) Effects of early starvation periods on zoeal development of brachyuran crabs. Biol Bull (Woods Hole) 161:199-212

Angilletta MJ Jr, Sears MW, Pringle RM (2009) Spatial dynamics of nesting behavior: Lizards shift microhabitats to construct nests with beneficial thermal properties. Ecology 90:2933-2939

Ashmore GM, Janzen FJ (2003) Phenotypic variation in smooth softshell turtles (Apalone mutica) from eggs incubated in constant versus fluctuating temperatures. Oecologia 134:182-188

> Asoh K, Yoshikawa T (2002) The role of temperature and embryo development time in the diel timing of spawning in a coral-reef damselfish with high-frequency spawning synchrony. Environ Biol Fishes 64:379-392

Bakun A (1990) Global climate change and intensification of coastal ocean upwelling. Science 247:198-201

> Barth JA, Menge BA, Lubchenco J, Chan F and others (2007) Delayed upwelling alters nearshore coastal ocean ecosystems in the northern California current. Proc Natl Acad Sci USA 104:3719-3724

> Beebee TJC (1995) Amphibian breeding and climate. Nature 374:219-220

Berens P (2009) CircStat: a MATLAB toolbox for circular statistics. J Stat Softw 31: www.jstatsoft.org/v31/i10/paper

Bernardo J (1996) Maternal effects in animal ecology. Am Zool 36:83-105

Christopher CE, Salmon M, Forward RB Jr (2008) Is the hatching clock of fiddler crab larvae (Uca thayeri) phenotypically plastic? J Crustac Biol 28:328-333 
Christy JH (1982) Adaptive significance of semilunar cycles of larval release in fiddler crabs (genus Uca): test of an hypothesis. Biol Bull (Woods Hole) 163:251-263

Christy JH (2003) Reproductive timing and larval dispersal of intertidal crabs: the predator avoidance hypothesis. Rev Chil Hist Nat 76:177-185

Christy JH (2011) Timing of hatching and release of larvae by brachyuran crabs: patterns, adaptive significance and control. Integr Comp Biol 51:62-72

> Christy JH, Backwell PRY, Goshima S (2001) The design and production of a sexual signal: hoods and hood building by male fiddler crabs Uca musica. Behaviour 138:1065-1083

Collins M, An SI, Cai W, Ganachaud A and others (2010) The impact of global warming on the tropical Pacific Ocean and El Niño. Nat Geosci 3:391-397

Crane J (1941) Crabs of the genus Uca from the west coast of Central America. Zoologica (N Y) 26:145-208

Crawley MJ (2002) Statistical computing: an introduction to data analysis using S-Plus. John Wiley and Sons, New York

D'Croz L, O'Dea A (2007) Variability in upwelling along the Pacific shelf of Panama and implications for the distribution of nutrients and chlorophyll. Estuar Coast Shelf Sci 73:325-340

Danks HV (2002) Modification of adverse conditions by insects. Oikos 99:10-24

deRivera CE (2005) Long searches for male-defended breeding burrows allow female fiddler crabs, Uca crenulata, to release larvae on time. Anim Behav 70:289-297

Dollard HA (1980) Larval release patterns in the wharf crab, Sesarma cinereum, from North Inlet, South Carolina. MS thesis, University of South Carolina, Columbia, SC

$>$ Du WG, Shine R (2010) Why do the eggs of lizards (Bassiana duperreyi: Scincidae) hatch sooner if incubated at fluctuating rather than constant temperatures? Biol J Linn Soc 101:642-650

> Duguid WDP, Page LR (2011) Biennial reproduction with embryonic diapause in Lopholithodes foraminatus (Anomura: Lithodidae) from British Columbia waters. Invertebr Biol 130:68-82. doi:10.1111/j.1744-7410.2011. 00221.x

Dvořák J, Gvoždík L (2010) Adaptive accuracy of temperature oviposition preferences in newts. Evol Ecol 24:1115-1127

Edwards M, Richardson AJ (2004) Impact of climate change on marine pelagic phenology and trophic mismatch. Nature 430:881-884

> Georges A, Beggs K, Young JE, Doody JS (2005) Modelling development of reptile embryos under fluctuating temperature regimes. Physiol Biochem Zool 78:18-30

Hagstrum DW, Milliken GA (1991) Modeling differences in insect developmental times between constant and fluctuating temperatures. Ann Entomol Soc Am 84:369-379

> Harley CDG, Randall Hughes A, Hultgren KM, Miner BG and others (2006) The impacts of climate change in coastal marine systems. Ecol Lett 9:228-241

- Hovel KA, Morgan SG (1997) Planktivory as a selective force for reproductive synchrony and larval migration. Mar Ecol Prog Ser 157:79-95

> Huang WS, Pike DA (2011) Climate change impacts on fitness depend on nesting habitat in lizards. Funct Ecol 25: 1125-1136

Kokita T, Nakazono A (2000) Seasonal variation in the diel spawning time of the coral reef fish Oxymonacanthus longirostris (Monacanthidae): parental control of progeny development. Mar Ecol Prog Ser 199:263-270
Kordas RL, Harley CDG, O'Connor MI (2011) Community ecology in a warming world: the influence of temperature on interspecific interactions in marine systems. J Exp Mar Biol Ecol 400:218-226

> López-Duarte PC, Christy JH, Tankersley RA (2011) A behavioral mechanism for dispersal in fiddler crab larvae (genus $U_{C a}$ ) varies with adult habitat, not phylogeny. Limnol Oceanogr 56:1879-1892

> McGregor HV, Dima M, Fischer HW, Mulitza S (2007) Rapid 20th-century increase in coastal upwelling off northwest Africa. Science 315:637-639

> Milner RNC, Detto T, Jennions MD, Backwell PRY (2010) Experimental evidence for a seasonal shift in the strength of a female mating preference. Behav Ecol 21:311-316

> Morgan SG (1996) Plasticity in reproductive timing by crabs in adjacent tidal regimes. Mar Ecol Prog Ser 139:105-118

- Morgan SG, Christy JH (1995) Adaptive significance of the timing of larval release by crabs. Am Nat 145:457-479

Morgan SG, Christy JH (1997) Planktivorous fishes as selective agents for reproductive synchrony. J Exp Mar Biol Ecol 209:89-101

- Morgan SG, White JW, McAfee ST, Gaines SD, Schmitt RJ (2011) Weak synchrony in the timing of larval release in upwelling regimes. Mar Ecol Prog Ser 425:103-112

Narayan N, Paul A, Mulitza S, Schulz M (2010) Trends in coastal upwelling intensity during the late 20th century. Ocean Sci 6:815-823

Olson RR, Olson MH (1989) Food limitation of planktotrophic marine invertebrate larvae: does it control recruitment success? Annu Rev Ecol Syst 20:225-247

Palmer J (1995) The biological rhythms and clocks of intertidal animals. Oxford University Press, New York, NY

> Patterson LD, Blouin-Demers G (2008) The effect of constant and fluctuating incubation temperatures on the phenotype of black ratsnakes (Elaphe obsoleta). Can J Zool 86: 882-889

Pike DA, Webb JK, Shine R (2012) Hot mothers, cool eggs: nest-site selection by egg-guarding spiders accommodates conflicting thermal optima. Funct Ecol 26:469-475. doi:10.1111/j.1365-2435.2011.01946.x

R Development Core Team (2011) R: a language and environment for statistical computing, Version 2.13.0. R Foundation for Statistical Computing, Vienna. Available at: www.R-project.org

Rathbun MJ (1935) Preliminary description of six new species of crabs from the Pacific coast of America. Proc Biol Soc Wash 48:49-52

> Reaney LT, Backwell PRY (2007) Temporal constraints and female preference for burrow width in the fiddler crab, Uca mjoebergi. Behav Ecol Sociobiol 61:1515-1521

> Sanford E (1999) Regulation of keystone predation by small changes in ocean temperature. Science 283:2095-2097

Schwing FB, Bond NA, Bograd SJ, Mitchell T, Alexander MA, Mantua N (2006) Delayed coastal upwelling along the U.S. West Coast in 2005: a historical perspective. Geophys Res Lett 33:L22S01 doi:10.1029/2006GL026911

Shine R (2005) Life history evolution in reptiles. Annu Rev Ecol Evol Syst 36:23-46

Shine R, Harlow PS (1993) Maternal thermoregulation influences offspring viability in a viviparous lizard. Oecologia 96:122-127

Shine R, Elphick MJ, Harlow PS (1997) The influence of natural incubation environments on the phenotypic traits of hatchling lizards. Ecology 78:2559-2568

> Silva K, Vieira MN, Almada VC, Monteiro NM (2007) The 
effect of temperature on mate preferences and femalefemale interactions in Syngnathus abaster. Anim Behav 74:1525-1533

Smith WK, Miller PC (1973) The thermal ecology of two south Florida fiddler crabs: Uca rapax Smith and U. pugilator Bosc. Physiol Zool 46:186-207

Smyder EA, Martin KLM (2002) Temperature effects on egg survival and hatching during the extended incubation period of California grunion, Leuresthes tenuis. Copeia 2002:313-320

Snyder MA, Sloan LC, Diffenbaugh NS, Bell JL (2003) Future climate change and upwelling in the California Current. Geophys Res Lett 30:1823

Thackeray SJ, Sparks TH, Frederiksen M, Burthe S and others (2010) Trophic level asynchrony in rates of phenological change for marine, freshwater and terrestrial environments. Glob Change Biol 16:3304-3313

Visser ME, Holleman LJM, Gienapp P (2006) Shifts in caterpillar biomass phenology due to climate change and its impact on the breeding biology of an insectivorous bird. Oecologia 147:164-172

- Walther GR, Post E, Convey P, Menzel A and others (2002) Ecological responses to recent climate change. Nature 416:389-395

> Warkentin KM (2011a) Environmentally cued hatching across taxa: embryos respond to risk and opportunity. Integr Comp Biol 51:14-25

Warkentin KM (2011b) Plasticity of hatching in amphibians:

Editorial responsibility: Inna Sokolova,

Charlotte, North Carolina, USA evolution, trade-offs, cues and mechanisms. Integr Comp Biol 51:111-127

- Wear RG (1974) Incubation in British decapod Crustacea, the effects of temperature on the rate and success of embryonic development. J Mar Biol Assoc UK 54: $745-762$

- Weaver A, Salmon M (2002) Hatching rhythms of Uca thayeri: evidence for phenotypic plasticity. J Crustac Biol 22: 429-438

> Wheeler DE (1978) Semilunar hatching periodicity in the mud fiddler crab Uca pugnax (Smith). Estuaries 1: 268-269

Wickham H (2009) Ggplot2: elegant graphics for data analysis. Springer, New York, NY

Wood SN (2006) Generalized additive models: an introduction with R. Chapman \& Hall/CRC, Boca Raton, FL

> Yamahira K (1997) Hatching success affects the timing of spawning by the intertidally spawning puffer Takifugu niphobles. Mar Ecol Prog Ser 155:239-248

Zar JH (2010) Biostatistical analysis, 5th edn. Pearson Prentice Hall, Upper Saddle River, NJ

> Zucker N (1978) Monthly reproductive cycles in three sympatric hood-building tropical fiddler crabs (genus $U_{C a}$ ). Biol Bull (Woods Hole) 155:410-424

Zucker N (1983) Courtship variation in the neo-tropical fiddler crab Uca deichmanni: another example of female incitation to male competition? Mar Freshw Behav Physiol 10:57-79

Submitted: December 27, 2011; Accepted: May 21, 2012

Proofs received from author(s): July 1, 2012 